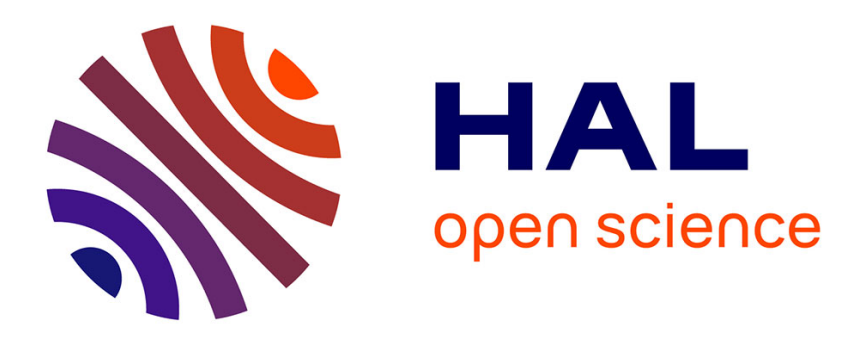

\title{
Taming Electron Transfers: From Breaking Bonds to Creating Molecules
}

\author{
Niklas von Wolff, Marc Robert
}

\section{To cite this version:}

Niklas von Wolff, Marc Robert. Taming Electron Transfers: From Breaking Bonds to Creating Molecules. The Chemical Record, In press, 10.1002/tcr.202100151 . hal-03265759

\section{HAL Id: hal-03265759 \\ https://hal.science/hal-03265759}

Submitted on 21 Jun 2021

HAL is a multi-disciplinary open access archive for the deposit and dissemination of scientific research documents, whether they are published or not. The documents may come from teaching and research institutions in France or abroad, or from public or private research centers.
L'archive ouverte pluridisciplinaire HAL, est destinée au dépôt et à la diffusion de documents scientifiques de niveau recherche, publiés ou non, émanant des établissements d'enseignement et de recherche français ou étrangers, des laboratoires publics ou privés. 
Taming Electron Transfers: From Breaking Bonds to Creating Molecules

Niklas von Wolff, ${ }^{*[a]}$ Marc Robert *[a],[b]

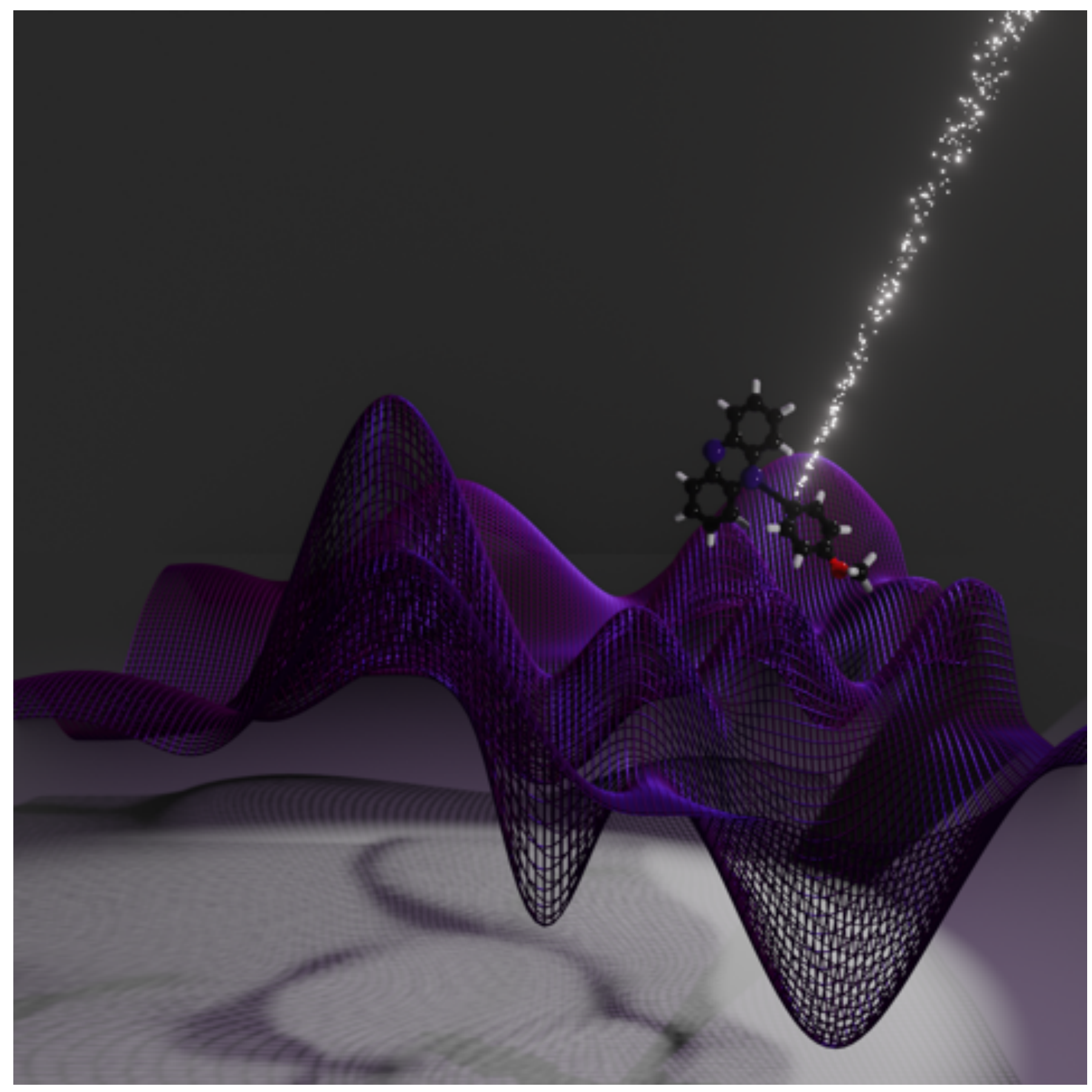


Abstract: The electron is the ultimate redox reagent to build and reshape molecular structures. Understanding and controlling the parameters underlying dissociative electron transfer (DET) reactivity and its coupling with proton transfer is crucial for combining selectivity, kinetics and energy efficiency in molecular chemistry. Reactivity understanding and mechanistic elements in DET processes are traced back and key examples of current research efforts are presented, demonstrating a large variety of applications. The involvement of DET pathways indeed encompasses a broad range of processes such as photoredox catalysis, $\mathrm{CO}_{2}$ reduction and alcohol oxidation. Interplay between these experimental examples and fundamental mechanistic study provides a powerful path to the understanding of driving force-rate relationships, which is crucial for the development of future generations of energy efficient catalytic schemes in redox organic chemistry.

\section{Introduction}

Our society is currently facing major challenges ranging from a global pandemic to climate change and environmental destruction. Innovative solutions are needed to guarantee human living conditions and a really sustainable economy for the times to come. Chemistry, which is responsible for roughly $25 \%$ of industrial energy consumption ${ }^{[1]}$ and at the heart of the pharmaceutical industry, can and must play a major role in overcoming current limitations in energy, bulk and healthcare-related domains. In terms of challenges for chemists, key goals include the development of atom and energy efficient processes, which necessitate cheap and renewable resources as well as excellent selectivity.

Electrochemistry combines many of the aspects necessary to achieve the goals of sustainability and selectivity. ${ }^{[2]}$ In particular, the electron as a redox equivalent is an ideal reagent, as it is cheap and possibly derived from renewable energy sources. ${ }^{[3]}$ Using electrons as redox agents also allows to avoid strongly oxidizing or reducing species, and thus increases atom efficiency and safety. As an illustrative example, Baran et al. recently developed a electrochemical Birch reduction, highlighting many of the advantages of electrochemistry in typical organic redox chemistry. ${ }^{[4]}$ Another important feature of using electrons as redox agents is energy efficiency. The energy input of a given reaction is indeed controlled via the applied potential. These advantages, together with more accessible equipment has led to a renewal of interest in electrochemistry. High quality reviews have been published that highlight the recent progress in the field and summarize main aspects of organic electrochemistry. ${ }^{[3 b, 5]}$

[a] Dr. N. von Wolff, Prof. Dr. M. Robert Université de Paris

Laboratoire d'Électrocimie Moléculaire, CNRS

F-75006 Paris, France

[b] Institut Universitaire de France (IUF)

F-75005 Paris, France
By essence, reductive molecular electrochemistry involves the transfer of electrons into empty or partially filled molecular orbitals and the challenge for the chemist is to orchestrate such transfers with efficient and selective bond breaking/formation processes (to cite the late Jean-Michel Savéant: "the transposition to oxidation is straightforward"). ${ }^{[6]}$ In this account, we tried to sketch the development of these dissociative electron transfers (DET) and to highlight their importance in modern chemical challenges, ranging from fast and selective processes in organic synthesis to energy related electrochemical processes, such as $\mathrm{CO}_{2}$ reduction or alcohol oxidation. ${ }^{[7]}$ Starting with a theoretical background on the cleavage of carbon element bonds by electron transfer, recent synthetic applications are then discussed. As an essential feature of chemical and biological redox chemistry, differences and similarities between dissociative electron transfer and protoncoupled electron transfer (CPET) will be given. ${ }^{\left[{ }^{[3]}\right.}$ Consequences in modern synthetic applications are provided, highlighting their importance for energy storage and conversion technology. Current limitations and future developments are finally discussed, with promising avenues to be explored.

Niklas von Wolff received his B.Sc. from the University of Zurich, a M.Sc. from University Pierre et Marie Curie and a Diploma from ENS Paris. After a PhD with Thibault Cantat and Jean-Claude Berthet at CEA Saclay, he was industrial postdoc fellow at Air Liquide and the University Paris Diderot under the guidance of Marc Robert and Jean-Michel Savéant. He then joined the group of Prof. David Milstein at the Weizmann Institute of Science as postdoc and visiting scientist, before integrating his current lab as CNRS researcher. He is recipient of a BASF thesis award from SCF-IdF, the $2^{\text {nd }}$ René Dabard thesis award from ENSCR (Rennes) and an excellence postdoc fellowship of the Israel Academy of Science and Humanities.

Marc Robert is a Professor of Chemistry at Université de Paris (UP) since 2004 and a Senior Fellow at the Institut Universitaire de France (IUF). He graduated $(\mathrm{PhD})$ from former Université Paris Diderot (Paris 7) under the guidance of Prof. Jean-Michel Savéant and was a postdoctoral fellow in the group of Prof. Matthew S. Platz at Ohio State University. $\mathrm{He}$ is a group leader at the Laboratoire d'Electrochimie Moléculaire (UP, CNRS). His interests include electrochemical and photochemical approaches of electrontransfer processes and the catalytic activation of small molecules, such as $\mathrm{CO}_{2}$, $\mathrm{H}_{2} \mathrm{O}$, and $\mathrm{N}_{2}$.

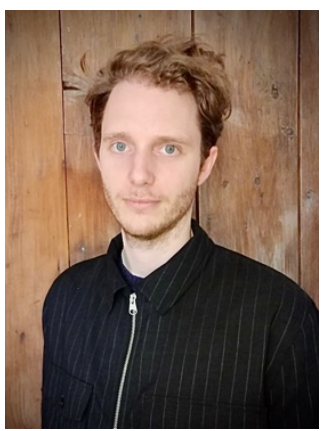

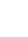




\section{Cleaving bonds with electrons}

\subsection{Background for (concerted) dissociative electron transfers}

Electron transfer to the frangible bond of a diamagnetic molecule to generate a radical and a diamagnetic ion (Scheme 1, reduction reaction) is at the heart of a rich radical and ionic (nucleophile/electrophile) reactivity. $\left.{ }^{[5 b}, 6\right]$ These dissociative electron transfers (DET) may be triggered at an electrode, which offers the possibility to easily control/tune the potential energy (driving force) for the reaction simply by changing the electrode applied potential, or with homogeneous donors in the ground or excited state when generated upon light excitation. Thus, there is a large range of experimental contexts and approaches for developing specific chemistry and catalysis upon DET. In these reactions, bond cleavage and charge transfer may be concerted (one transition state between reactant and product fragments, CDET) or stepwise, with an intermediate having a finite lifetime (longer than a vibration) and going through a barrier for cleavage (Scheme 1). ${ }^{[9]}$ The two pathways are competing parallel pathways and the competition between them is set by thermodynamic parameters including bond dissociation energy, energy of the radical anion (intermediate species in the sequential pathway) and oxidability of the leaving group (see below).

Beyond the concerted or sequential nature of the process, the exact understanding and if possible control of the reaction pathway can lead to efficient generation of intermediates (e.g radical species) as key intermediate in a more complex reaction scheme. For example, and as illustrated in the next section, the formation of a key radical species (e.g. phenyl radical in Scheme 3) can be optimized in terms of efficiency and fast production rate, then leading to an overall efficient process.

Outersphere electron transfer modeling developed by Hush and Marcus does not apply to concerted dissociative electron transfers as the harmonic vibration approximation for the internal reorganization energy is not compatible with the cleavage of a bond. Instead, Savéant has proposed a two state model with a Morse curve approximation of the energy of the cleaving bond in the reactant side and with the assumption that the repulsive interaction of the fragments product is the same as the repulsive part of the reactant Morse curve (Scheme 2). ${ }^{[10]}$ A quadratic activation-driving force relationship (equation 1) could then be obtained from calculating the transition state (crossing of the two potential curves), with a contribution to the reorganization energy being $D$, the homolytic bond dissociation energy of the cleaving bond. In addition, solvent reorganization $\left(\lambda_{0}\right)$ also contributes to the barrier, leading to the following equations governing the kinetics of the charge transfer:

$\Delta G^{\neq}=\Delta G_{0}^{\neq}\left(1+\frac{\Delta G^{0}}{4 \Delta G_{0}^{\neq}}\right)^{2}$ with $\Delta G_{0}^{\neq}=\frac{D+\lambda_{0}}{4}$

(equation 1)

where the driving force $\Delta G^{0}=E-E^{0}\left(R X / R^{\bullet}+X^{-}\right)$in the case of a reductive electron transfer, $E$ being the potential of the donor ( $E_{\text {electrode }}$ for an electrochemical reaction, $E_{\text {donor }}^{0}$ in the case of an homogeneous reaction). The competition between the sequential and the concerted pathway is thermodynamically controlled by the difference between the two standard redox potentials, which amounts to the standard free enthalpy of cleavage of the radical anion:

$\Delta G^{0}$ cleavage $=E^{0}\left(R X / R X^{\bullet}\right)-E^{0}\left(R X / R^{\bullet}+X^{-}\right)$

$=D-E^{0}\left(X^{\bullet} / X^{-}\right)+E^{0}\left(R X / R X^{\bullet}\right)-T \Delta S_{R X / R_{\bullet}+X_{\bullet}}$

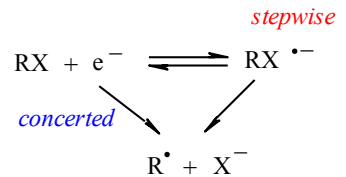

e- : electrode, homogeneous donor (ground state, excited state)

Scheme 1. Dissociative electron transfer (reduction reaction). Concerted and sequential pathway.

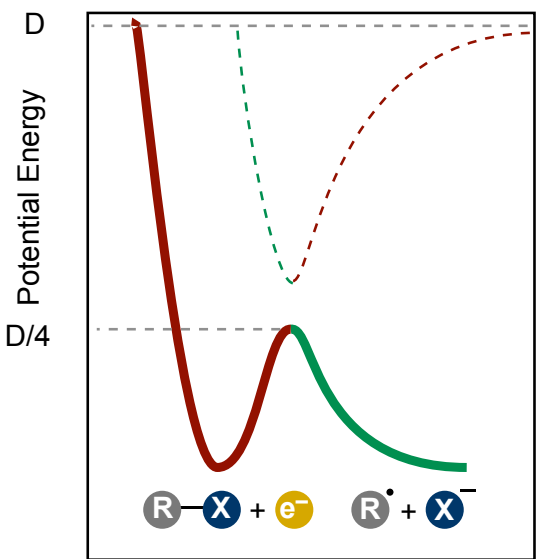

Bond Length

Scheme 2. Morse curve model for a concerted dissociative electron transfer (case of a reduction reaction). Potential energy of the reactant $R X$ is modelled by a Morse curve and the energy of the products $R^{\bullet}+X$ - by the repulsive part of reactant's curve, $D$ being the $R-X$ bond dissociation energy.

It is thus predicted that the weaker the cleaving bond (small value of $D$ ), the higher the energy of the radical anion intermediate (negative value of $E^{0}\left(R X / R X^{-}\right)$) and the easier the oxidability of the leaving group (positive value of $E^{0}\left(X^{\bullet} / X^{-}\right)$), the more favorable the concerted pathway will be. The entropic term is dominated by solvent effects on the caged and separated anion and radical fragments, and remains small (typically 0.2-0.3 eV). These three parameters have been experimentally identified in various families or organic substrates to indeed control the mechanism for reductive cleavage and their systematic variation has led to the observation of transition between the two pathways. ${ }^{[11]}$ The electrochemical reduction of aryldialkyl sulfonium cations at a carbon electrode provides a remarkable illustrative example of a mechanistic change (sequential vs. concerted) upon varying the bond dissociation energy of the cleaving $\mathrm{C}-\mathrm{S}$ bond and the energy of the sulfur radical species (Scheme 3 ). ${ }^{[11 \mathrm{c}]}$

As already mentioned, besides thermal heterogeneous or homogeneous reductive induction of dissociative electron transfer, the reaction may also be triggered photochemically upon using an 
excited sensitizer. In general, the driving force for electron transfer in such conditions would be larger than in electrochemical conditions, thus intrinsically favouring stepwise pathways, and

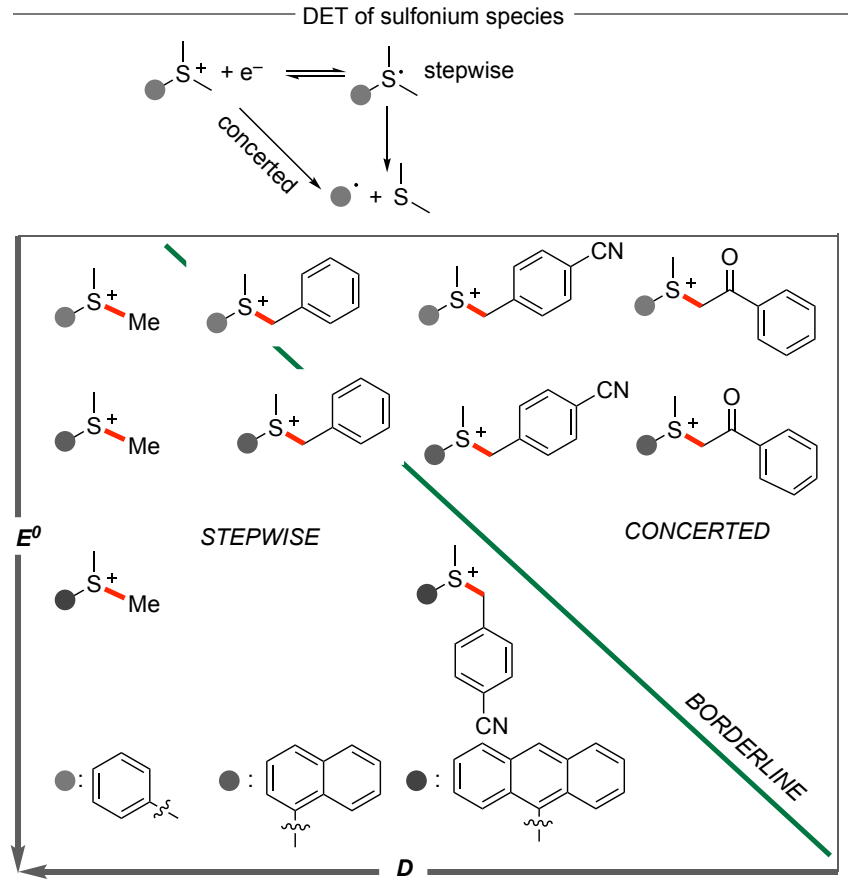

also favouring efficient bond cleavages due to the high energy of the donor. ${ }^{[12]}$

Scheme 3. Dissociative electron transfer to aryldialkyl sulfoniums cations. Mechanistic pathway upon electrochemical reduction as a function of the bond dissociation energy $(D)$ of the C-S bond being cleaved and of the energy of the sulfur centred radical intermediate species $\left(E^{0}\left(R^{+} / R S^{\bullet}\right)\right)$.

\subsection{Recent applications of dissociative electron transfer reactivity in organic synthesis}

Intimate understanding of the different parameters outlined above that govern the scission of strong bonds by electron transfer has led to a variety of applications. In particular, over the last decade, photoredox catalysis has evolved as a highly prolific research domain in organic chemistry. ${ }^{[13]}$ Among the many intriguing examples issued from this field, we have selected a few of them that highlight the importance of dissociative electron transfer in promoting otherwise inaccessible reaction pathways.

As a first example dealing with ${ }^{18} \mathrm{~F}$-chemistry, the Ritter group has designed novel late-stage fluorination strategies. ${ }^{[14]}$ By developing a site-selective aromatic $\mathrm{C}-\mathrm{H}$ thianthrenation, it is now possible to introduce this versatile functionality into complex molecular architectures. ${ }^{[15]}$ Importantly, the thianthrene-group is not only an excellent coupling partner in common transition metal catalyzed cross coupling reactions, but the cationic charge on sulfur also makes it an excellent leaving group in dissociative electron transfer schemes. ${ }^{[11 \mathrm{c}]} \mathrm{Cu}$-based catalysts for late-stage functionalization are promising due to efficient reductive $\mathrm{C}-\mathrm{F}$ elimination from possible $\mathrm{Cu}$ (III) intermediates (Scheme 4). Ritter and co-workers pointed out that the scaling relationship between reduction potential and cleavage rate of aryl halide heavily limits possible strategies towards the formation of such $\mathrm{Cu}(\mathrm{III})$ intermediates via oxidative ligation with aryl radicals. ${ }^{[16]}$ Indeed, in general low reduction potentials of aryl halide species would yield fast oxidative ligation, but would preclude formation of the $\mathrm{Cu}$ (III) intermediates necessary for effective reductive elimination and $\mathrm{C}-\mathrm{F}$ bond formation. Comparing e.g. aryl bromides and aryl thianthrene-based sulfonium salts gave cleaving rates 10 -orders of magnitude larger for the latter at a given driving force (reduction potential).

Ritter et al. 2020
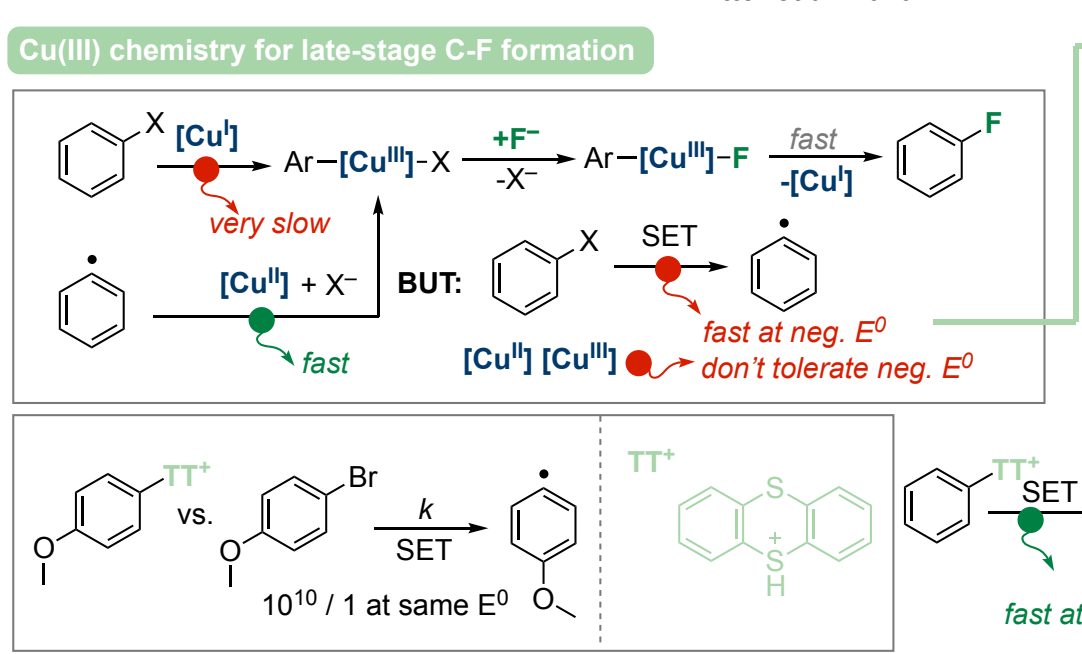

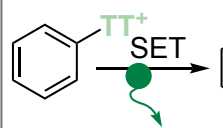

fast at mild $E^{0}$
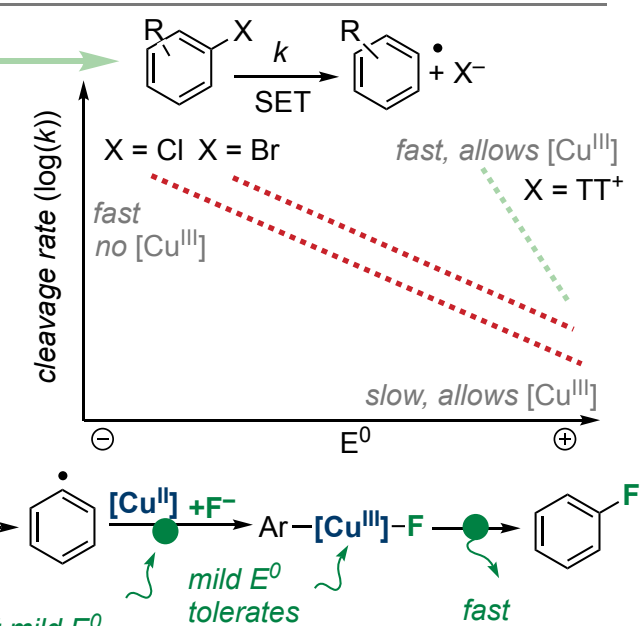

Scheme 4. Caveats and opportunities for $\mathrm{Cu}^{\mathrm{III}}$ chemistry for late-stage C—F bond formation.

These salts therefore allow for fast kinetics of the oxidative ligation without compromising $\mathrm{Cu}(\mathrm{III})$-chemistry due to low reduction potentials. From electrochemical data derived from in-depth cyclic voltammetry studies, a stepwise mechanism limited by the initial electron transfer was proposed for the reductive cleavage of the sulfonium species. ${ }^{[11 \mathrm{c}, 11 \mathrm{~d}, 17]}$ Combining these thianthrene-based 
aryl sulfonium salts in a photoredox process (with an iridium complex as photosensitizer) allowed for successful late-stage fluorination of a variety of substrates, including sensitive functional groups such as halides and pseudo-halides, aldehydes and alcohols. ${ }^{[16]}$

The König group demonstrated that highly reductive electron donors can be obtained via a two-photon photoredox process (Scheme 5), thus overcoming the classical limits imposed by visible light photons $(2.8 \mathrm{eV}$ at $440 \mathrm{~nm}) .{ }^{[18]}$ Using perylene diimide dyes, which possess stable colored ground-state radical anions, strong reduction equivalents can be generated. ${ }^{[19]}$ The driving force provided by the electron donor after two-photon absorption was sufficient to promote efficient aryl-chloride bond scission upon electron transfer, thus extending the scope of aryl(pseudo)halide precursor that could be used under visible light photoredox catalysis. ${ }^{[13 d, 13 f]}$ Similarly, Wickens and co-workers recently developed an electron-primed photoredox process able to generate donors with reductive potential as negative as $-3.3 \mathrm{~V}$ vs SCE (Scheme 6). ${ }^{[20]}$ Using an electrode as terminal reductant helped to gain better control over the reaction and to avoid the secondary chemistry related to the use of chemical ET-donors such as triethylamine. Screening of diimide photoredox catalysts led identifying a naphthalene-based system that upon electronpriming (reduction at ca. $-1.3 \mathrm{~V}$ vs SCE) and irradiation can generate sufficient driving forces to engage a variety of arylchlorides in phosphorylation and (hetero)arylation reactions. Importantly, diimides with lower reduction potentials (e.g. $-1.4 \mathrm{~V}$ vs SCE) were not competent catalysts, most likely due to overreduction at such low potentials of the intermediate radical anion. ${ }^{[21]}$ Despite generated reductions potentials beyond that of $\mathrm{Li}^{0}$, reducible functional groups such as nitriles, esters and amides were tolerated, highlighting the advantages of this electronprimed photoredox process.

In parallel, Lambert, Lin and co-workers reported a similar system (Scheme 6), based on dicyanoanthracene, that upon reduction and blue light excitation $\left(\lambda_{\max } \sim 450 \mathrm{~nm}\right)$ generates a highly reducing excited state radical anion (reductive potential of ca. -3.2 $\checkmark$ vs SCE). ${ }^{[22]} A$ variety of aryl chlorides underwent successful borylation, stannation and $\mathrm{C}-\mathrm{C}$ coupling under these conditions, again tolerating reducible functional groups such as esters, amides and acidic $\mathrm{C}-\mathrm{H}$ bonds.

\section{Two photon generation of strong SET dono}

$\Delta G$

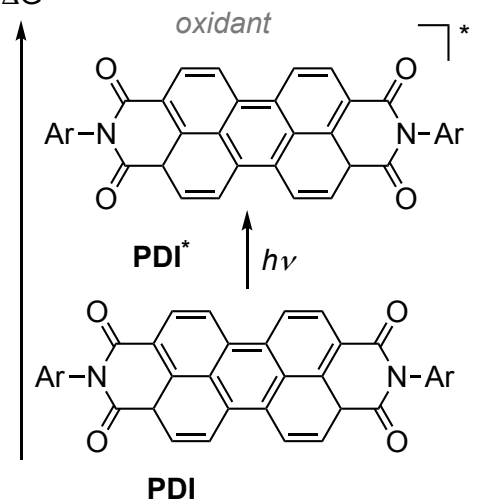

König et al. 2014

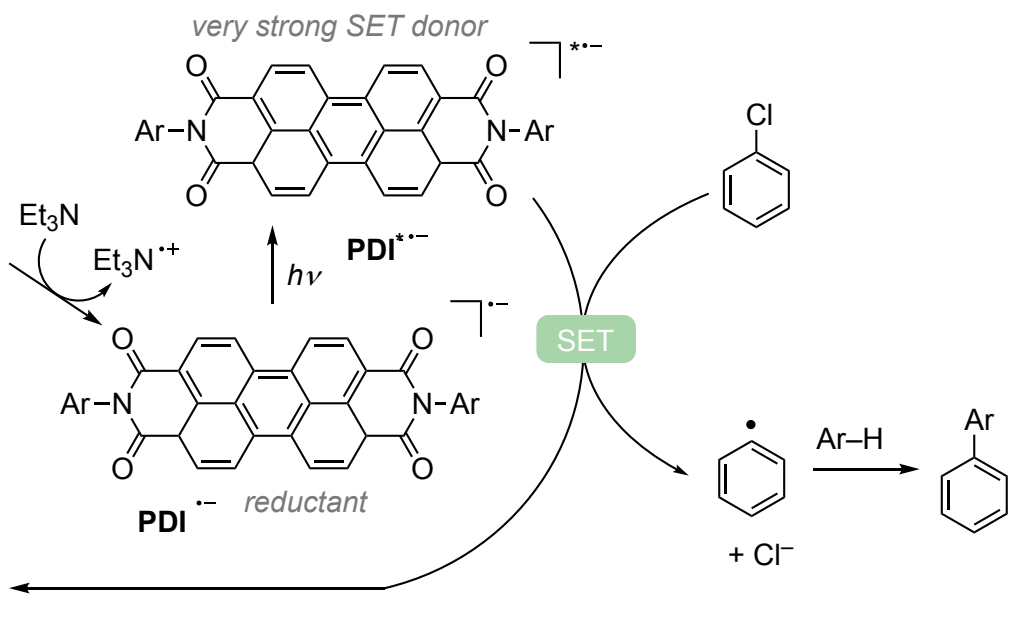

Scheme 5. Sequential two-photon (visible) one electron excitation of PDI generates a sufficiently strong SET donor for Ar-Cl cleavage. ${ }^{[18]}$ 
Wickens et al. 2020

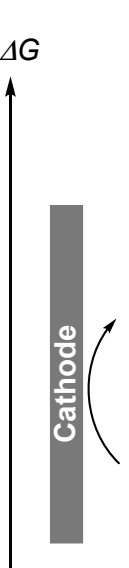

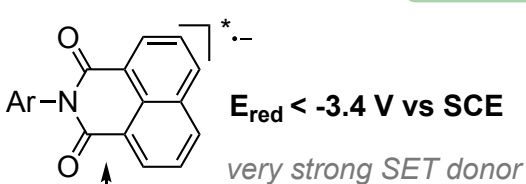
hv

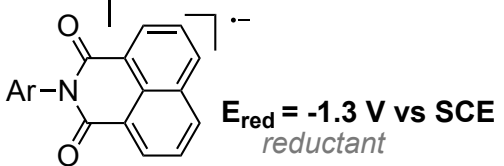

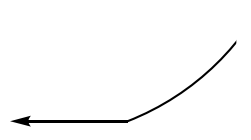

Lin et al. 2020<smiles>N#Cc1c2ccccc2c(C#N)c2ccccc12</smiles>

Scheme 6. So-called "electron-primed" photoredox catalysis generates strong SET donors for the efficient cleavage of Ar-CI bonds. ${ }^{[20,22]}$

The Lin group also explored a variety of electrocatalytic alkene functionalization reactions, such as dichlorinations, demonstrating the potential of electricity-driven metal catalysis. ${ }^{[5 e}$, 23] Morandi et al. developed synthetic routes to access and use such difunctionalized alkenes and other substrates in novel catalytic shuttle reactions (Scheme 7). ${ }^{[24]}$ These shuttle (de)hydrofunctionalization reactions rely on a facile and fast $\mathrm{B}-\mathrm{H}$ elimination step, which is favored over $B-X$ eliminations. This approach is thus not directly transposable to catalytically shuttle two functional groups at once. Importantly, together with the Waldvogel group, Morandi and co-workers showed that dissociative electron transfer pathways can be used to overcome bottlenecks in conventional shuttle catalysis schemes. ${ }^{[25]}$ In constant current electrolysis conditions, 1,2-dichloro species were reductively cleaved to mono-chlorinated radicals, that readily expel chloride after further reduction. Mn(II)-electrocatalysts could then oxidize (at the anode) the alkene co-substrate to the corresponding dichloride in a domino paired electrolysis setup. [23a] Importantly, polychlorinated substrates were also efficiently dehalogenated to the corresponding alkenes in the presence of a $\mathrm{Cl}_{2}$-acceptor. This procedure was for example applied for full dechlorination of lindane, a persistent organic pollutant. The approach is highly robust, tolerating impurities. It was thus possible to directly use lindane-contaminated soil samples as chlorine donors. This novel electron-shuttle catalysis scheme is a powerful tool for future developments in transfer difunctionalization reactions. Further mechanistic studies would be beneficial to understand limiting steps and kinetics, as well as 
a possible role of the manganese catalysts also in the reductive cleavage of the carbon chlorine bonds.

Waldvogel, Morandi et al. 2021

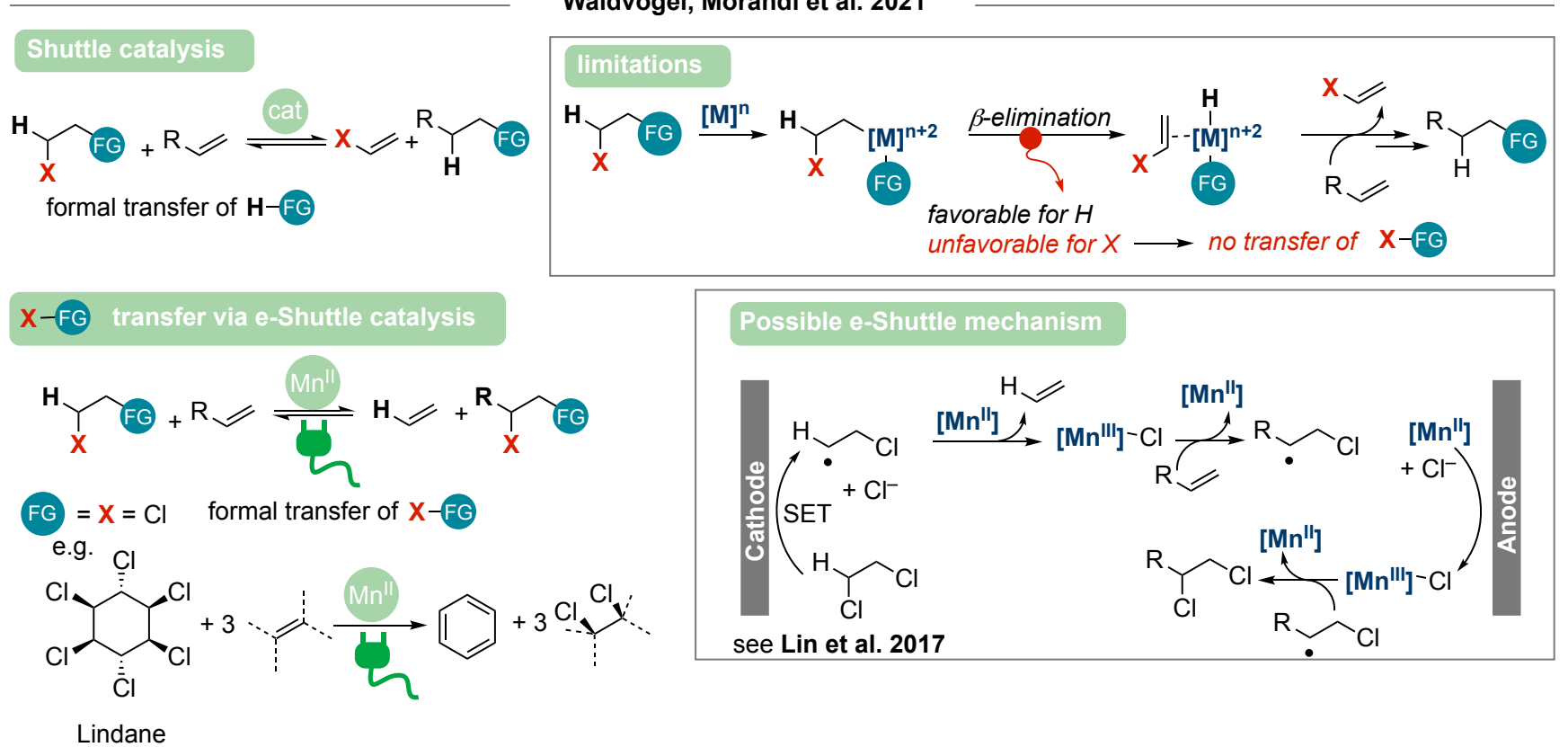

Scheme 7. Development of an e-shuttle catalytic scheme (two functional groups shuttling) to overcome limitations of current (hydro)functionalization shuttle catalysis. ${ }^{[25]}$

These examples highlight the important role that dissociative electron transfer schemes exert in modern organic synthesis. They also show how a detailed mechanistic picture of the elementary steps and rate constants may allow to fine-tune the reactivity and to develop highly selective processes under mild conditions.

In the next section, we illustrate how coupling the dissociative electron transfer to a proton transfer can influence the energetics and reaction sequence of bond scissions, as well as how catalysts can be used to finely control new reaction pathways.

\section{Reducing and cleaving bonds with electrons and protons}

\subsection{Proton coupled electron transfer (PCET)}

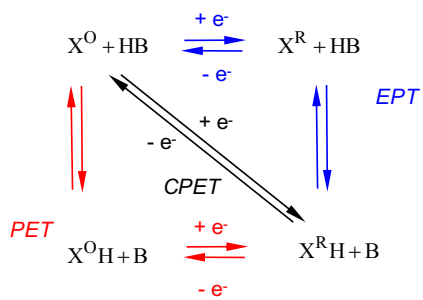

Scheme 8. Proton Coupled Electron Transfer (PCET), concerted (black, CPET) and sequential (red, proton first then electron transfer; blue, electron first, then proton transfer) pathways.
PCET reactions involving different sites for proton transfer and electron transfer, as it is the case for an electrochemical PCET, may involve stepwise and concerted processes (Scheme 8), similarly to a dissociative electron transfer process. The kinetic modelling of such reactions may be achieved with a double BornOppenheimer type approximation which treats the electron as a fast sub-system with respect to the proton and the proton as a fast sub-system with respect to heavy-atoms displacements (Scheme 9). ${ }^{26]}$

As for dissociative electron transfer, a concerted pathway will avoid generating high energy intermediate, such the reduced form $X^{R}$ of the oxidized reactant $X^{O}$ sketch in Scheme 8 , but with a kinetic penalty which does not arise from large reorganization (until the electron and proton transfer are also coupled to a bond breaking process, see below) but rather arises from a small preexponential factor due to non-adiabatic effects for electron and proton transfers occurring in the transition state. Experimental examples of concerted PCET reactions have been found both with organic molecules, e.g. in the electrochemical oxidation of phenol intramolecularly bonded to a pendant amine base in an organic solvent (acetonitrile), ${ }^{[27]}$ and with inorganic compounds 
such as in the electrochemical oxidation of an Os"-aquo complex in aqueous solution. ${ }^{[28]}$

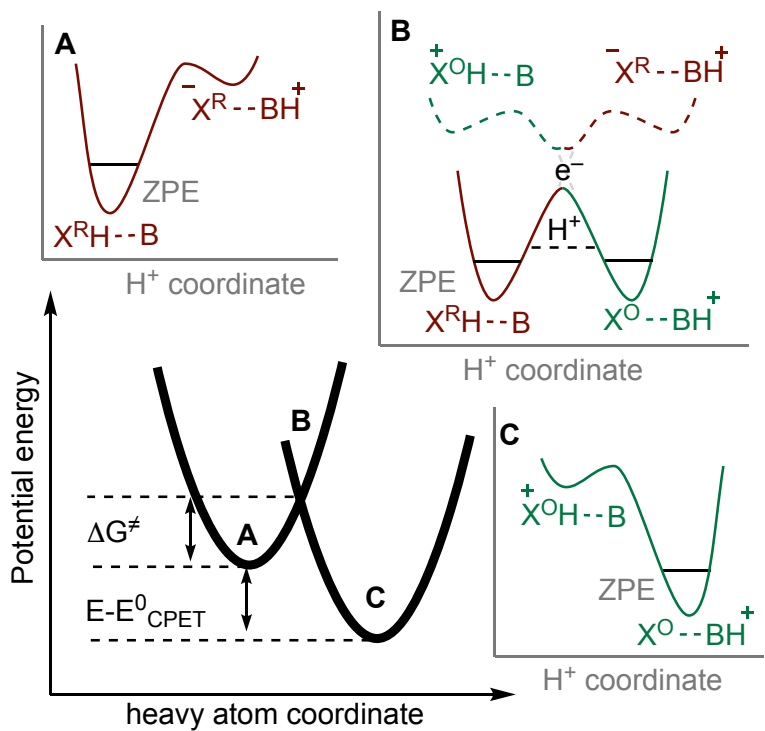

Scheme 9. Potential energy curves modeling for a CPET reaction. Reactants and product electronic state potential energies as a function of heavy-atoms reaction coordinate are described by parabolas. Inserts (A, B and C) show potential energies as a function of proton coordinate. ZPE: zero-point vibrational energy.

Catalytic reactions involving proton-coupled electron transfer(s) may in addition be coupled to bond breaking between heavy atoms. This is for example the case in $\mathrm{CO}_{2}$ reduction to $\mathrm{CO}$ where electron transfer reduction of the gas leads to $\mathrm{C}-\mathrm{O}$ bond breaking, in conjunction with protonation of the leaving oxygen atoms. In such case, the possibility that these events would be partially or totally concerted is an important aspect, that would give, in the latter case, a highly efficient process (see section 3.2.1 for an example). Such total concertation has been modeled. ${ }^{[29]}$ As in the CPET case, successive applications of the Born-Oppenheimer approximation allowed to describe the transition state in terms of a heavy atom coordinate (the same Morse curves that were used in the model of DET replace the parabolas shown in Scheme 9) and the pre-exponential factor in terms of a proton coordinate. Heavy atom reorganization mainly includes the solvent molecules and the contribution of bond cleavage. In such cases, kinetic penalty arises both from the contribution of the bond dissociation energy to the intrinsic barrier $(D / 4$ where $D$ is the homolytic bond dissociation energy) and from the low value of the pre-exponential factor due to tunneling of the electron and proton in the transition state of the reaction.

\subsection{Recent applications of CPET}

\subsubsection{Small molecule activation}

A striking example of an all concerted reaction involving both electron transfer, proton transfer and cleavage of a bond between heavy atoms has been identified in the catalytic reduction of $\mathrm{CO}_{2}$ to $\mathrm{CO}$ by electrogenerated $\mathrm{Fe}(0)$ tetraphenylporphyrin in DMF in the presence of a Brönsted acid (e.g. phenol or water) as a cosubstrate ${ }^{[30]}$ After binding between $\mathrm{CO}_{2}$ and the $\mathrm{Fe}$ of the reduced porphyrin, it was shown that the key step is an intramolecular electron transfer from the metal to the $\sigma^{*}$ orbital of the $\mathrm{C}-\mathrm{O}$ bond, leading to bond breaking concertedly with the protonation of the leaving oxygen by the added acid. The remarkably efficient and fast catalysis stems from this concertation which requires a perfect match between the catalyst, the substrate and the proton source, and may be designed on rational grounds if and only if mechanistic studies have assessed the intimate details of the mechanism. Beside $\mathrm{CO}_{2}$ catalytic reduction, PCET processes coupled to bond breaking/bond forming process may play a key role in a variety of processes related to small molecule activation, such as the reduction of dioxygen to hydrogen peroxide (2 electron- 2 proton reduction) or water (4 electron- 4 proton reduction), as well as in the reduction of nitrogen to ammonia.

\subsubsection{Beyond small molecule activation: Carbonyl reduction, alcohol oxidation}

In the previous section, the beneficial role of catalysts in orchestrating concerted ET and PT for efficient bond scission was outlined. In particular, in the case of electrocatalytic $\mathrm{CO}_{2}$ reduction, the efficiency of the catalyst can be benchmarked in terms of overpotential and turnover frequency using catalytic Tafel-plots. It highlights the potential of electrochemistry to control and monitor the energy efficiency of catalytic redox reaction. In view of the large energy footprint of the chemical industry, it is indeed highly desirable to create new atom and energy efficient catalytic pathways for common redox reactions. In that sense, recently developed photoredox catalytic Birch-reductions are an important contribution towards sustainable organic redox chemistry. ${ }^{[31]}$

Electrocatalytic carbonyl reductions. Apart from the many advances made in the field of electrocatalytic $\mathrm{CO}_{2}$ reduction, the catalytic and energy efficient reduction of other carbonyl groups have attracted less attention. Nevertheless, all the reactivity principles outlined above should be applicable to the reduction of carbonyl groups in general. Since early reports on $\mathrm{Ru}, \mathrm{Rh}$ and Irbased molecular catalysts for electrochemical ketone hydrogenation especially by Moutet and co-workers, it is only recently that new systems were reported. ${ }^{[32]}$ As shown for molecular $\mathrm{CO}_{2}$ and proton reduction, proton relays within the ligand framework can help bond breaking/formation via coupled proton and electron transfer. ${ }^{[33]}$ Using a homobimetallic manganese complex based on phenol-functionalized ligand backbone, the Siewert group showed that $\mathrm{Mn}-\mathrm{H}$ species could be formed cathodically via PT/ET sequences. The hydride species generated upon electron and proton transfer were active in reducing a variety of aliphatic ketones. Importantly, the $2 \mathrm{e}^{-} / 2 \mathrm{H}^{+}$ reduction of the carbonyl moiety tolerated to a certain extent the presence of $\mathrm{C}-\mathrm{C}$ double bonds. ${ }^{[34]}$

The Waymouth group recently investigated the possibility to use a Shvo-type Molybdenum complex for electrocatalytic hydrogenations. ${ }^{[35]}$ Protonation of the solvated Mo(0)cyclopentadienone complex yielded a new cationic Mo(II) species. 
Reduction via two electron transfer reactions (either with cobaltocene or electrochemically) coupled to another proton transfer delivers a stable and spectroscopically characterized $\mathrm{Mo}(\mathrm{II})-\mathrm{H}$ species. Under controlled potential electrolysis conditions, benzaldehyde was successfully reduced to benzyl alcohol with 4.4 turnovers and Faradaic efficiencies (FE) of $67 \%$, ${ }^{[36]}$ even though no catalytic currents were observed in cyclic voltammetry.

In the absence of carbonyl substrate activation, pathways relying on sequential electron-proton transfer might be inhibited by too negative reduction potentials. Besides the possibility to use hydride transfer pathways (see above), Peters et al. recently achieved electrocatalytic concerted proton-electron transfer (eCPET) strategies for carbonyl reduction. ${ }^{[37]}$ Similar approaches have already been investigated for the reverse reaction, i.e. the oxidation of alcohols using electrocatalytic HAT-systems based on nitroxyl-radicals (for a discussion of HAT vs. CPET see e.g. ref $\left.{ }^{[38]}\right)^{[38-39]}$ The advantage of the eCPET approach are promisingly lower overpotentials and good selectivity by avoiding the hydrogen evolution reaction (HER). On the other hand, low bond dissociation free energies (BDFE) in the newly formed bond of the carbon-centered radical $(20-40 \mathrm{kcal} / \mathrm{mol}$, Scheme 10) heavily restraint possible eCPET candidates. It was previously shown that cobaltocene derivatives could be excellent electron mediators and PCET agents, with potentially very weak $\mathrm{C}-\mathrm{H}$ bonds as HAT donors (BDFE around $30 \mathrm{kcal} / \mathrm{mol}$ ). ${ }^{[40]}$ However, due to strong rearrangements at carbon and of the $\mathrm{Cp}$-bonding to Co, Peters and co-workers proposed to append a nitrogen-based Brønsted acid to the ligand backbone (Scheme 10, bottom). Reduction of the cobaltocene core (Co(III) to $\mathrm{Co}(\mathrm{II}))$ weakens the $\mathrm{N}-\mathrm{H}$ bond drastically, lowering the $\mathrm{BDFE}_{\mathrm{N}-\mathrm{H}}$ by $40 \mathrm{kcal} / \mathrm{mol}$ (Scheme 10). CV studies demonstrated a rate-limiting CPET step. The system was catalytic active under preparative conditions with turnovers over 40 for the reduction of acetophenone, albeit with moderate selectivity (FE\% of 39 , with HER as the main sidereaction), producing only a $1 \mathrm{H}^{+} / 1 \mathrm{e}^{-}$reduction product (the corresponding pinacol derived from the homocoupling of the radical intermediate). Despite these shortcomings, the study highlights the high potential for eCPET molecular based platforms and demonstrates the importance of carefully deciphering thermodynamic and kinetic reaction parameters.

Peters et al. 2020

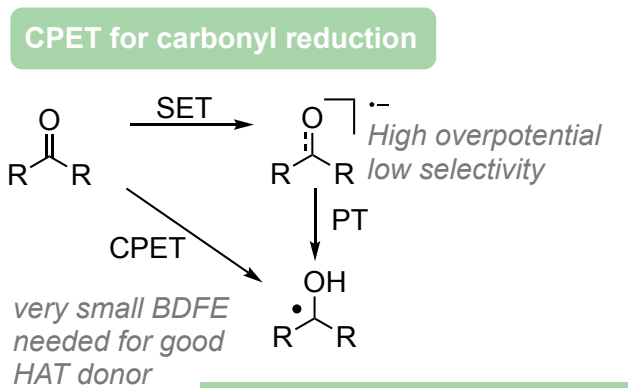

HAT donor

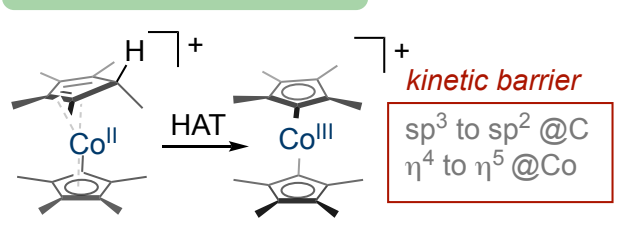

$B D F E_{C-H}=29 \mathrm{kcal} / \mathrm{mol}$

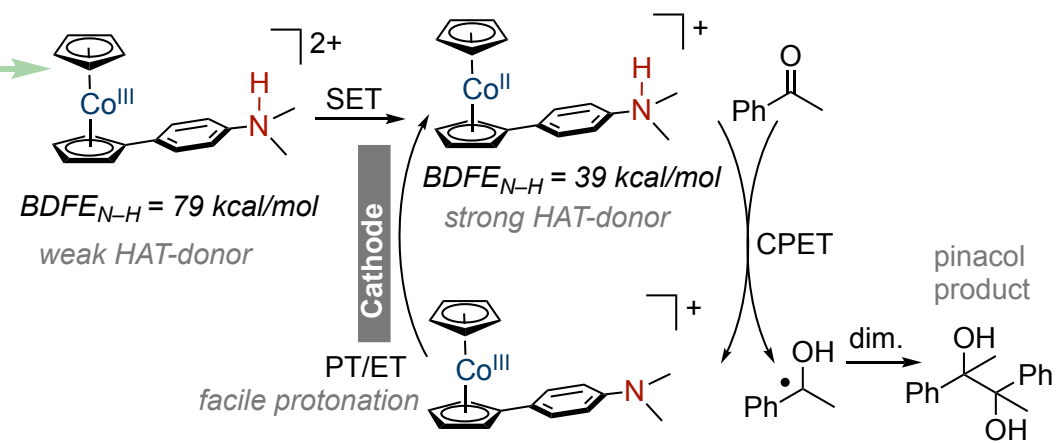

Decoupling of ET and PT site:

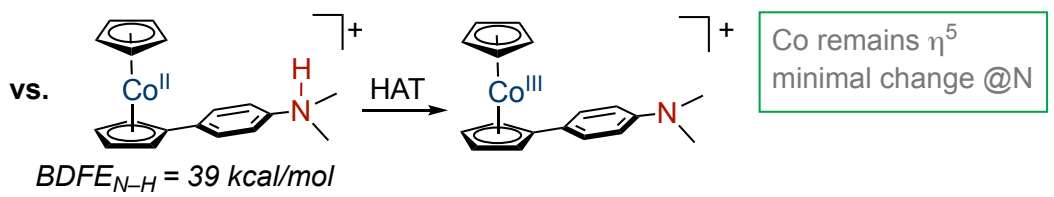

Scheme 10. Rational design of a strong CPET donor for electrocatalytic reduction of carbonyl species by decoupling ET and PT sites. ${ }^{[37]}$

Electrocatalytic alcohol oxidation. The reverse process, i.e. the electrocatalytic alcohol oxidation is equally important to achieve the goal of an energy efficient redox chemistry. In addition, electrifying alcohol oxidation reaction could have a direct impact for the development of efficient and economically-beneficial anodic reaction to be implemented e.g. in $\mathrm{CO}_{2}$ electrolyzers by lowering cell-voltage and offering value-added by-products. ${ }^{[41]}$ In particular, nitroxyl radical-based systems have been explored for electrocatalytic $2 \mathrm{H}^{+} / 2 \mathrm{e}^{-}$oxidations by the Stahl group and recent progress has been reviewed. ${ }^{[39]}$ Other avenues explore the use of transfer hydrogenation complex as catalyst candidates such as seminal work by the Grützmacher group that demonstrated the feasibility of an organometallic fuel cell. ${ }^{[42]}$ The Waymouth grouped extended the field of catalysts to acceptorless dehydrogenation systems, albeit with very limited turnover. ${ }^{[43]} A$ summary of progress and challenges in the field was recently published. ${ }^{[\mathrm{b}]}$ Combining transfer dehydrogenation catalysts with HAT-mediators allowed the Waymouth group to circumvent less efficient sequential ET/PT pathways extending the scope to a selected example of a $4 \mathrm{H}^{+} / 4 \mathrm{e}^{-}$product. $^{[44]}$

\section{Conclusion and Outlook}


Electrochemistry will likely play a major role in the future in domains ranging from safe, selective and energy efficient organic chemistry via energy storing and transportation applications to highly important small molecule activations for renewable $\mathrm{N}$ - and $\mathrm{C}$-feedstock generation. Understanding the underlying principles governing bond(s) breaking via electron transfer was proven to be essential to develop processes at the forefront of molecular chemistry of today. In particular, in the case of many component systems, where strong constrains are imposed on reaction rates and redox potential windows, an intimate knowledge of the factors governing bond dissociation pathways and kinetics can be highly beneficial. This was demonstrated in the example of the Ritter group, where high rates in a small potential range were needed to achieve high catalysis rate. Redox photocatalysis illustrates how strong driving forces can be generated to cleave even aromatic $\mathrm{C}-\mathrm{Cl}$ bonds efficiently, while conserving high degree of selectivity.

Analyzing these driving force-rate relationships in the presence of protons (PCET) helped to gain important knowledge that was successfully implemented in the design of molecular electrocatalysts for $\mathrm{CO}_{2}$ reduction and alcohol oxidation. Developing even better-performing systems in these domains will be indeed crucial to overcome the hurdles towards a more sustainable economy. It thus remains critical to pursue the development of in-depth understanding of DET reactivity.

\section{Acknowledgements}

Funding from the IdEx Université de Paris 2019, ANR-18-IDEX0001 is acknowledged (NvW).

\section{ORCID}

$\begin{array}{ll}\text { Niklas von Wolff } & 0000-0001-8108-5365 \\ \text { Marc Robert } & 0000-0001-7042-4106\end{array}$

Keywords: dissociative electron transfer - proton-coupled electron transfer - photocatalysis - small molecule activation electrocatalysis

[1] Chemicals, IEA, Paris, 2020, https://www.iea.org/reports/chemicals

[2] Y. Yuan, A. Lei, Nature Communications 2020, 11, 802.

[3] a) B. A. Frontana-Uribe, R. D. Little, J. G. Ibanez, A. Palma, R. VasquezMedrano, Green Chem. 2010, 12, 2099-2119; b) T. H. Meyer, I. Choi, C. Tian, L. Ackermann, Chem 2020, 6, 2484-2496.

[4] B. K. Peters, K. X. Rodriguez, S. H. Reisberg, S. B. Beil, D. P. Hickey, Y. Kawamata, M. Collins, J. Starr, L. Chen, S. Udyavara, K. Klunder, T. J. Gorey, S. L. Anderson, M. Neurock, S. D. Minteer, P. S. Baran, Science 2019, 363, 838.

[5] a) R. Francke, R. D. Little, Chem. Soc. Rev. 2014, 43, 2492-2521; b) Organic Electrochemistry: Revised and Expanded, 5th ed., CRC Press., 2015; c) M. Yan, Y. Kawamata, P. S. Baran, Chem. Rev. 2017, 117 13230-13319; d) C. Kingston, M. D. Palkowitz, Y. Takahira, J. C Vantourout, B. K. Peters, Y. Kawamata, P. S. Baran, Acc. Chem. Res. 2020, 53, 72-83; e) J. C. Siu, N. Fu, S. Lin, Acc. Chem. Res. 2020, 53
547-560; f) C. Schotten, T. P. Nicholls, R. A. Bourne, N. Kapur, B. N. Nguyen, C. E. Willans, Green Chem. 2020, 22, 3358-3375.

[6] J.-M. Savéant, Elements of Molecular and Biomolecular Electrochemistry: An Electrochemical Approach to Electron Transfer Chemistry, John Wiley \& Sons, Inc., Hoboken, NJ, USA, 2006.

[7] a) C. Costentin, M. Robert, J.-M. Savéant, Chem. Soc. Rev. 2013, 42 , 2423-2436; b) A. W. Cook, K. M. Waldie, ACS Appl. Energy Mater. 2020, 3, 38-46; c) K. Torbensen, B. Boudy, D. Joulié, N. von Wolff, M. Robert, Current Opinion in Electrochemistry 2020, 24, 49-55.

[8] a) S. Hammes-Schiffer, Acc. Chem. Res. 2009, 42, 1881-1889; b) C Costentin, M. Robert, J.-M. Savéant, Acc. Chem. Res. 2010, 43, 10191029; c) S. Hammes-Schiffer, Energy Environ. Sci. 2012, 5, 7696-7703; d) D. R. Weinberg, C. J. Gagliardi, J. F. Hull, C. F. Murphy, C. A. Kent, B. C. Westlake, A. Paul, D. H. Ess, D. G. McCafferty, T. J. Meyer, Chem. Rev. 2012, 112, 4016-4093.

[9] C. Costentin, M. Robert, J.-M. Savéant, Chemical Physics 2006, 324, 4056.

[10] J. M. Saveant, J. Am. Chem. Soc. 1987, 109, 6788-6795.

[11] a) C. P. Andrieux, A. Le Gorande, J. M. Saveant, J. Am. Chem. Soc. 1992, 114, 6892-6904; b) C. P. Andrieux, E. Differding, M. Robert, J. M. Saveant, J. Am. Chem. Soc. 1993, 115, 6592-6599; c) C. P. Andrieux, M. Robert, F. D. Saeva, J. M. Saveant, J. Am. Chem. Soc. 1994, 116, 7864-7871; d) C. P. Andrieux, J.-M. Savéant, A. Tallec, R. Tardivel, C. Tardy, J. Am. Chem. Soc. 1997, 119, 2420-2429.

[12] a) L. Pause, M. Robert, J.-M. Savéant, J. Am. Chem. Soc. 2001, 123, 4886-4895; b) C. Costentin, M. Robert, J.-M. Savéant, J. Phys. Chem. A 2000, 104, 7492-7501

[13] a) D. A. Nicewicz, D. W. C. MacMillan, Science 2008, 322, 77-80; b) J. M. R. Narayanam, C. R. J. Stephenson, Chem. Soc. Rev. 2011, 40, 102113; c) Y.-Q. Zou, J.-R. Chen, W.-J. Xiao, Angewandte Chemie International Edition 2013, 52, 11701-11703; d) I. Ghosh, L. Marzo, A. Das, R. Shaikh, B. König, Acc. Chem. Res. 2016, 49, 1566-1577; e) N. A. Romero, D. A. Nicewicz, Chem. Rev. 2016, 116, 10075-10166; f) J. P. Barham, B. König, Angewandte Chemie International Edition 2020, 59, 11732-11747.

[14] M. G. Campbell, T. Ritter, Org. Process Res. Dev. 2014, 18, 474-480.

[15] a) F. Berger, M. B. Plutschack, J. Riegger, W. Yu, S. Speicher, M. Ho, N. Frank, T. Ritter, Nature 2019, 567, 223-228; b) J. Chen, J. Li, M. B. Plutschack, F. Berger, T. Ritter, Angewandte Chemie International Edition 2020, 59, 5616-5620; c) X.-X. Nie, Y.-H. Huang, P. Wang, Org. Lett. 2020, 22, 7716-7720.

[16] J. Li, J. Chen, R. Sang, W.-S. Ham, M. B. Plutschack, F. Berger, S. Chabbra, A. Schnegg, C. Genicot, T. Ritter, Nature Chemistry 2020, 12, 56-62.

[17] C. Costentin, M. Robert, J.-M. Savéant, J. Am. Chem. Soc. 2004, 126, 16051-16057.

[18] I. Ghosh, T. Ghosh, J. I. Bardagi, B. König, Science 2014, 346, 725-728.

[19] a) H. Lund, J. Simonet, Journal of Electroanalytical Chemistry and Interfacial Electrochemistry 1975, 65, 205-218; b) P. Nelleborg, H. Lund, J. Eriksen, Tetrahedron Letters 1985, 26, 1773-1776.

[20] N. G. W. Cowper, C. P. Chernowsky, O. P. Williams, Z. K. Wickens, J. Am. Chem. Soc. 2020, 142, 2093-2099.

[21] C. P. Andrieux, J. Pinson, J. Am. Chem. Soc. 2003, 125, 14801-14806.

[22] H. Kim, H. Kim, T. H. Lambert, S. Lin, J. Am. Chem. Soc. 2020, 142, 2087-2092.

[23] a) N. Fu, G. S. Sauer, S. Lin, J. Am. Chem. Soc. 2017, 139, 1554815553; b) J. Liu, L. Lu, D. Wood, S. Lin, ACS Cent. Sci. 2020, 6, 13171340 .

[24] a) B. N. Bhawal, B. Morandi, ACS Catal. 2016, 6, 7528-7535; b) T. Delcaillau, P. Boehm, B. Morandi, J. Am. Chem. Soc. 2021, 143, 3723 3728; c) M. D. R. Lutz, B. Morandi, Chem. Rev. 2021, 121, 300-326; d) Y. H. Lee, E. H. Denton, B. Morandi, Nature Chemistry 2021, 13, 123130.

[25] X. Dong, J. L. Roeckl, S. R. Waldvogel, B. Morandi, Science 2021, 371 507. 
[26] a) R. I. Cukier, D. G. Nocera, Annual Review of Physical Chemistry 1998 49, 337-369; b) C. Costentin, M. Robert, J.-M. Savéant, Journal of Electroanalytical Chemistry 2006, 588, 197-206.

[27] C. Costentin, M. Robert, J.-M. Savéant, J. Am. Chem. Soc. 2007, 129, 9953-9963.

[28] C. Costentin, M. Robert, J.-M. Savéant, A.-L. Teillout, Proc Natl Acad Sci USA 2009, 106, 11829-11836.

[29] C. Costentin, V. Hajj, M. Robert, J.-M. Savéant, C. Tard, Proc Natl Acad Sci USA 2011, 108, 8559-8564.

[30] C. Costentin, S. Drouet, G. Passard, M. Robert, J.-M. Savéant, J. Am. Chem. Soc. 2013, 135, 9023-9031.

[31] a) A. Chatterjee, B. König, Angewandte Chemie International Edition 2019, 58, 14289-14294; b) J. P. Cole, D.-F. Chen, M. Kudisch, R. M. Pearson, C.-H. Lim, G. M. Miyake, J. Am. Chem. Soc. 2020, 142, 1357313581.

[32] a) I. M. F. De Oliveira, J.-C. Moutet, Journal of Molecular Catalysis 1993, 81, L19-L24; b) S. Chardon-Noblat, I. M. F. de Oliveira, J.-C. Moutet, S. Tingry, Journal of Molecular Catalysis A: Chemical 1995, 99, 13-21; c) J.-C. Moutet, L. Yao Cho, C. Duboc-Toia, S. p. Me' nage, E. C. Riesgo, R. P. Thummel, New J. Chem. 1999, 23, 939-944; d) A. Deronzier, J. C. Moutet, in Comprehensive Coordination Chemistry II (Eds.: J. A McCleverty, T. J. Meyer), Pergamon, Oxford, 2003, pp. 471-507; e) Z. Chen, C. R. K. Glasson, P. L. Holland, T. J. Meyer, Phys. Chem. Chem. Phys. 2013, 15, 9503-9507.

[33] a) C. Costentin, S. Drouet, M. Robert, J.-M. Savéant, Science 2012, 338 90; b) B. H. Solis, A. G. Maher, D. K. Dogutan, D. G. Nocera, S. HammesSchiffer, Proc Natl Acad Sci USA 2016, 113, 485-492; c) B. Mondal, A Dey, Chem. Commun. 2017, 53, 7707-7715.

[34] I. Fokin, I. Siewert, Chemistry - A European Journal 2020, 26, 14137 14143.

[35] a) Y. Shvo, D. Czarkie, Y. Rahamim, D. F. Chodosh, J. Am. Chem. Soc. 1986, 108, 7400-7402; b) W. Wu, T. Seki, K. L. Walker, R. M. Waymouth, Organometallics 2018, 37, 1428-1431; c) K. C. Armstrong, R. M. Waymouth, Organometallics 2020, 39, 4415-4419.

[36] The Faradaic efficiency (FE\%) being the ratio between the number of electrons used to form the product and the total number of electrons passed during electrolysis. $\mathrm{FE} \%$ is thus linked to the $\mathrm{TON}$ : $\mathrm{FE} \%=$ $\frac{\mathrm{N} \times \mathrm{TON} \times \mathrm{n}_{\text {cat }}}{\mathrm{O}}$ with $N=$ electron stoichiometry, $n_{\text {cat }}=$ mol of catalyst, $Q=$ total charge passed and $F=$ Faraday constant.

[37] M. J. Chalkley, P. Garrido-Barros, J. C. Peters, Science 2020, 369, 850.

[38] J. E. M. N. Klein, G. Knizia, Angewandte Chemie International Edition 2018, 57, 11913-11917.

[39] a) A. Badalyan, S. S. Stahl, Nature 2016, 535, 406; b) F. Wang, S. S. Stahl, Acc. Chem. Res. 2020, 53, 561-574.

[40] a) R. Cai, R. D. Milton, S. Abdellaoui, T. Park, J. Patel, B. Alkotaini, S. D. Minteer, J. Am. Chem. Soc. 2018, 140, 5041-5044; b) M. J. Chalkley, P. H. Oyala, J. C. Peters, J. Am. Chem. Soc. 2019, 141, 4721-4729.

[41] a) J. Na, B. Seo, J. Kim, C. W. Lee, H. Lee, Y. J. Hwang, B. K. Min, D. K. Lee, H.-S. Oh, U. Lee, Nature Communications 2019, 10, 5193; b) S. Verma, S. Lu, P. J. A. Kenis, Nature Energy 2019, 4, 466-474.

[42] a) S. P. Annen, V. Bambagioni, M. Bevilacqua, J. Filippi, A. Marchionni, W. Oberhauser, H. Schönberg, F. Vizza, C. Bianchini, H. Grützmacher Angewandte Chemie International Edition 2010, 49, 7229-7233; b) M. Bellini, M. Bevilacqua, A. Marchionni, H. A. Miller, J. Filippi, H. Grützmacher, F. Vizza, European Journal of Inorganic Chemistry 2018 2018, 4393-4412.

[43] E. A. McLoughlin, B. D. Matson, R. Sarangi, R. M. Waymouth, Inorganic Chemistry 2020, 59, 1453-1460.

[44] a) E. A. McLoughlin, K. C. Armstrong, R. M. Waymouth, ACS Catal. 2020, 10, 11654-11662; b) C. M. Galvin, R. M. Waymouth, J. Am. Chem. Soc. 2020, 142, 19368-19378. 


\section{PERSONAL ACCOUNT}

Breaking bonds selectively in complex molecular systems is key in both energy related and synthetic applications. This personal account traces back how the fine understanding of dissociative electron transfer allowed for the development of systems ranging from late-stage fluorination, photoredox catalysis to alcohol oxidation and small molecule activation.

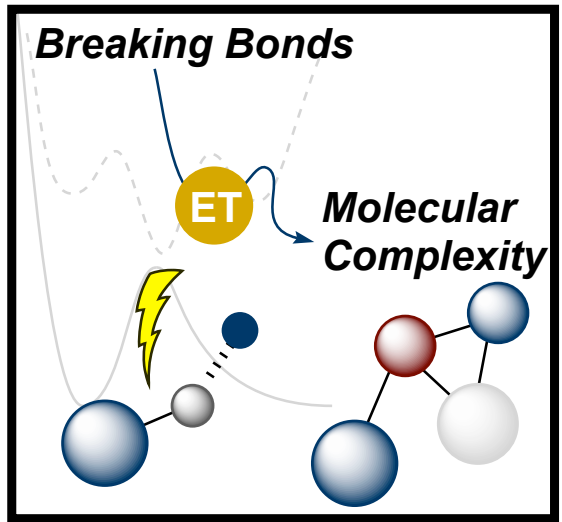

Niklas von Wolff*, Marc Robert*

Page No. - Page No.

Title

Layout 2:

\section{PERSONAL ACCOUNT}

((Insert TOC Graphic here))
Author(s), Corresponding Author(s)*

Page No. - Page No.

Title

Text for Table of Contents 